Tạp chí Khoa học và Công nghệ biển T11 (2011). Số 1. Tr 1 - 13

\title{
LÁNG ĐỌNG TRÀ̀M TÍCH TRÊN BÃI TRIỀU \\ BÀNG LA VÀ NGỌC HẢI, HẢI PHÒNG
}

\section{ĐẶNG HOÀI NHOON, HOÀNG THỊ CHIẾN, NGUYẼ̃N THỊ KIM ANH, BÙI VĂN VƯợNG, NGUYẼ̃N NGỌC ANH, PHẠM HẢI AN, VŨ MẠNH HÙNG}

\author{
Viện Tài nguyên và Môi trường biển
}

\author{
PHAN SƠN HẢI
}

Viện Hạt nhân Đà Lạt

Tóm tắt: Lắng đọng trầm tích trên bãi triều Bàng La - Ngọc Hải, Hải Phòng đã được nghiên cứu bằng bẫy và lỗ khoan trầm tích. Bẫy trầm tích được nghiên cứu trong 2 mùa trong các năm 2008 và 2009, tuổi lỗ khoan trầm tích đuợc xác định bằng 210Pb sử dụng mô hình CRS để tính.

Trầm tích lắng đọng và tầng mặt trên bãi triều là các trầm tích có kích thuớc hạt nhỏ, gồm 3 loại trầm tích là bột lớn $(M d=0,057-0,087 \mathrm{~mm})$, bùn bột nhỏ $(M d=0,010-0,025$ $\mathrm{mm})$, bùn sét bột $(\mathrm{Md}=0,008-0,009 \mathrm{~mm})$.

Bãi triều Bàng La có tốc độ tích tu khối luọng trầm tích về mùa khô dao động trong khoảng $1,34-6,98 \mathrm{~g} / \mathrm{cm} 2 /$ năm, về mùa mia trong khoảng $0,07-13,76 \mathrm{~g} / \mathrm{cm} 2 /$ năm. Bãi triều Ngọc Hải có tốc độ tích tu khối luợng trầm tích về mùa khô dao động trong khoảng 1,82 $6,84 \mathrm{~g} / \mathrm{cm} 2 /$ năm, về mùa mura trong khoảng $8,55-22,81 \mathrm{~g} / \mathrm{cm} 2 /$ năm.

Tốc độ bồi tu nổi cao ở bãi triều Bàng La dao động trong khoảng 0,13 - 1,18 cm/năm trong giai đoạn 1894 - 2008, tốc độ bồi tu nổi cao ở bãi triều Ngọc Hải dao động trong khoảng 0,26 - 15,00 cm/năm trong giai đoạn 1935 - 2008.

Lắng đọng trầm tích trên bãi triều chịu ảnh huởng rất lớn của thảm thực vật ngập mặn và vị trí của địa hình. Kết quả đo được cho thấy tốc độ tích tu khối luợng trầm tích lớn nhất gặp trong rùng ngập mặn, bên ngoài rù̀ng ngập mặn có tốc độ tích tu khối luoọng trầm tích nhỏ hơn.

Tù khóa: ${ }^{210} \mathrm{~Pb}$, lắng đọng trầm tích, bãi triều, Bàng La, Ngọc Hải.

\section{MỞ ĐÀ̀U}

Nghiên cứu quá trình lắng đọng trầm tích trên bãi triều có ý nghĩa trong việc bảo vệ, chống xói lở bờ biển, và đánh giá quá trình mở rộng bãi triều ven biển. Vai trò của rừng 
ngập mặn trong dải ven bờ được xem như là tác nhân làm giảm năng lượng sóng, giảm tốc độ dòng chảy tạo điều kiện cho quá trình lắng đọng diễn ra, quá trình này đã được đề cập nhiều ở Việt Nam nhưng là những nghiên cứu mang tính định tính. Các con số mang tính định lượng về tốc độ lắng đọng bao nhiêu và lắng đọng như thế nào vẫn còn là vấn đề mới và ít tài liệu công bố ở Việt Nam đặc biệt với ven bờ Hải Phòng.

Lắng đọng trầm tích đã được nghiên cứu khá sớm (Nguyễn Quang Tuấn và Nguyễn Chu Hồi, 1999; Đặng Hoài Nhơn, 2008) nhưng là những nghiên cứu trên rạn san hô trên ven bờ Hải Phòng - Quảng Ninh. Sau này, các nghiên cứu của các tác giả nước ngoài (Van den Bergh G.D. et al., 2007; Santen P.V. et al., 2007; Janssen-Steldera B.M . et al., 2002) đã tiến hành nghiên cứu lắng đọng trầm tích ở cửa sông Ba Lạt. Lắng đọng trầm tích còn được nghiên cứu ở bãi triều Kim Sơn của tỉnh Ninh Bình (Trần Đình Lân và Trần Đức Thạnh, 1991), khu vực Tây Nam Đồ Sơn (Bùi Văn Vượng và Đinh Văn Huy, 2006). Bài báo này góp phần làm sáng tỏ quá trình lắng đọng trầm tích trên các bãi triều Bàng La và Ngọc Hải, Hải Phòng.

\section{TÀI LIỆU VÀ PHƯƠNG PHÁP NGHIÊN CÚU}

\section{Tài liệu}

Tài liệu trình bày trong bài báo này là kết quả của hai đợt khảo sát vào mùa khô năm 2008 và mùa mưa năm 2009 tại bãi triều Bàng La và Ngọc Hải (hình 1).

Trên bãi triều Bàng La và Ngọc Hải mỗi bãi triều khảo sát 1 mặt cắt, mỗi mặt cắt có 4 trạm bẫy trầm tích tại các vị trí khác nhau từ bãi triều cao đến bãi triều trung. Tại phần rìa ngoài của rừng ngập mặn chúng tôi đã thu mẫu hai lỗ khoan, một ở bãi triều Bàng La có tọa độ $20^{\circ} 41^{\prime} 48^{\prime}$ ' $\mathrm{N}-106^{0} 44^{\prime} 24^{\prime}$ 'E và một ở bãi triều Ngọc Hải có tọa độ $20^{0} 43^{\prime} 28^{\prime}$ ' $\mathrm{N}$ - 106 47'26' 'E. Lỗ khoan thu tại bãi triều Bàng La có chiều dài $40 \mathrm{~cm}$, tại bãi triều Ngọc Hải có chiều dài $60 \mathrm{~cm}$. Mẫu các lỗ khoan này được cắt có độ dày $1-3 \mathrm{~cm}$ đem phân tích ${ }^{210} \mathrm{~Pb},{ }^{226} \mathrm{Ra}$ tại Viện Nghiên cứu Hạt nhân Đà Lạt.

\section{Phương pháp nghiên cứu}

\section{Bố trí thí nghiệm bẫy ngoài hiện truò̀ng}

Bẫy trầm tích đặt trong bãi triều có thực vật ngập mặn từ bãi triều cao đến bãi triều trung được chia ra làm các đoạn như đầu rừng ngập mặn, giữa rừng ngập mặn, chân rừng ngập mặn và ngoài rừng ngập mặn. Tại mỗi điểm đặt 3 bẫy. Bẫy được làm bằng vải bạt nilong (canvas) có kích thước $40 \times 40 \mathrm{~cm}$ được đặt sát xuống mặt bãi quan trắc 24 giờ 
trong kỳ nước cường. Sau 24 giờ, trầm tích lắng đọng trên mặt bẫy được thu mang về phòng thí nghiệm phân tích.

\section{Tính tốc độ tích lũy khối trầm tích}

Mẫu bẫy sau khi được thu đem rửa mặn và loại bỏ lá cây, các vật bất thường rồi sấy khô đem cân và phân tích thành phần độ hạt. Sau đó tính tốc độ tích lũy khối lượng trầm tích bằng công thức (1):

$$
\mathrm{vg}=\mathrm{m} / \mathrm{s} / \mathrm{t}
$$

Trong đó:

vg: khối lượng tích lũy trầm tích $\left(\mathrm{g} / \mathrm{cm}^{2} / \mathrm{năm}\right)$;

m: khối lượng $(\mathrm{g})$ trầm tích trên mặt bẫy;

s: diện tích mặt bẫy $\left(\mathrm{cm}^{2}\right)$;

t: thời gian (năm)

\section{Phưong pháp phân tích độ hạt trầm tích}

Trầm tích bẫy sau khi đã được loại bỏ muối và vật chất hữu cơ được phân tích bằng rây cho cấp hạt trầm tích lớn hơn $0,063 \mathrm{~mm}$ và pipét phân tích các cấp hạt nhỏ hơn 0,063 mm, phân loại trầm tích theo Lisitzin A.P. (1986).

\section{Phương pháp phân tích ${ }^{210} \mathrm{~Pb},{ }^{226} \mathrm{Ra}$}

Phân tích hoạt độ ${ }^{210} \mathrm{~Pb}$ tổng số $\left({ }^{210} \mathrm{~Pb}_{\text {tổng }}\right)$ có trong lỗ khoan trầm tích bằng máy quang phổ anpha sau khi đã phá mẫu với axít và cho hấp phụ ${ }^{210} \mathrm{~Pb}$ với đĩa bạc (Phan Sơn Hải, 1999). ${ }^{226}$ Ra trong trầm tích được đo trực tiếp mẫu trên máy quang phổ gama. ${ }^{210} \mathrm{~Pb}_{\mathrm{du}}$

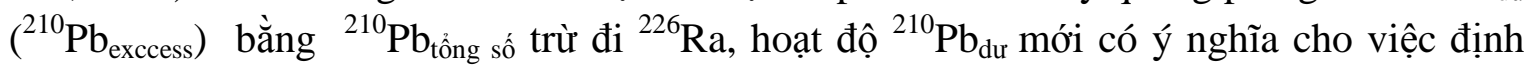
tuổi trầm tích.

\section{Mô hình tính tuổi trầm tích}

Việc lựa chọn mô hình để tính tuổi trầm tích, tốc độ bồi tụ nổi cao phụ thuộc vào nhiều yếu tố. Nhiều mô hình tính tuổi đã được các nhà khoa học trên Thế giới sử dụng như mô hình CIC (constant initial concentration), CIA (constant initial activity), CSA (constant specific activity), CF-CS (constant flux - constant sedimention), CRS (constant rate of supply), SIT (sediment isotope tomography), ứng với mô hình người ta có những điều kiện để áp dụng. Chúng tôi chọn mô hình CRS để tính, bởi vì mô hình này được nhiều nhà khoa học sử dụng tính tuổi trầm tích cho các thủy vực ven bờ. Mô hình định tuổi $\mathrm{CRS}$ của ${ }^{210} \mathrm{~Pb}$ được đưa ra (Krishnaswami S. et al., 1971) và sau này được phát triển (Appleby P.G. and Oldfield F., 1978; Robbins J.A., 1978; Appleby P.G., Oldfield F., 
1992) và đến nay đã được sử dụng rộng rãi. Các công thức tính tuổi trầm tích (2) và tốc độ bồi tụ nổi cao (3) ở dưới đây.

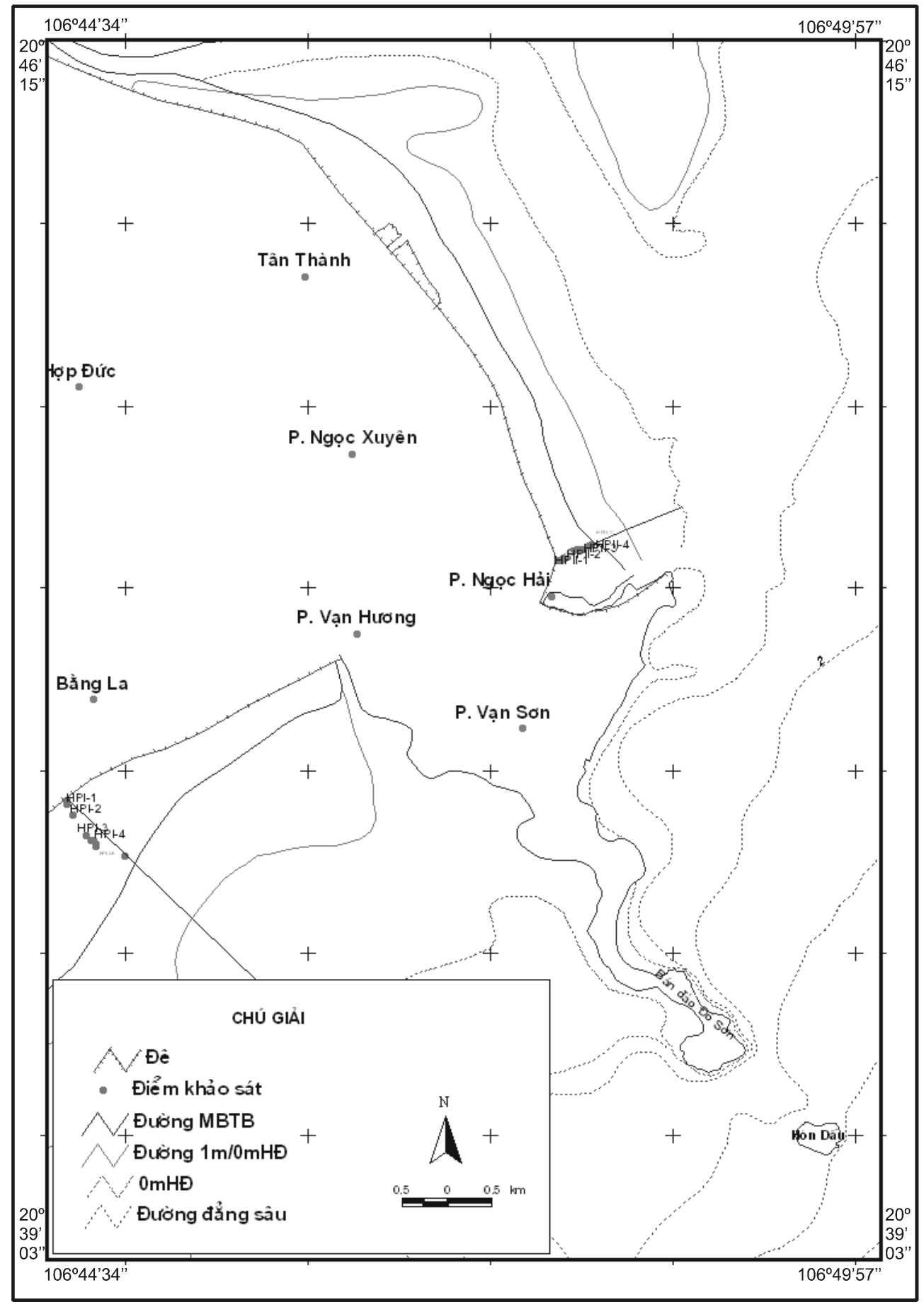

Hình 1: Sơ đồ khu vực nghiên cứu 
$t=\frac{1}{\lambda} \ln \left(\frac{A(0)}{A(x)}\right)$

Trong đó:

t: thời gian (năm);

$\lambda$ : hằng số $=0,031$;

$\mathrm{A}(0)$ : tổng lượng ${ }^{210} \mathrm{~Pb}_{\mathrm{du}}$ trong cột khoan $\left({ }^{210} \mathrm{~Pb}_{\mathrm{du}}\right)$;

$\mathrm{A}(\mathrm{x})$ : lượng ${ }^{210} \mathrm{~Pb}_{\mathrm{du}}$ tích lũy đến độ sâu $\mathrm{x}$.

Tốc độ bồi tụ nổi cao $(v h)$ của thủy vực được tính theo công thức 3 sau:

$v h=\frac{l}{t_{n}-t_{n-1}}$

vh: tốc độ bồi tụ nổi cao (cm/năm)

$l$ : bề dày của lát cắt trầm tích (ví dụ lát cắt dày $2 \mathrm{~cm}, 3 \mathrm{~cm}$ ):

$t_{n}$ và $t_{n-1}$ : là thời gian (năm) ứng với mỗi lát cắt thứ $\mathrm{n}, \mathrm{n}-1$ trong lỗ khoan tính theo công thức (2)

\section{KẾT QUẢ NGHIÊN CÚU}

\section{1. Đặc điểm trầm tích tầng mặt và trầm tích lắng đọng trên bãi triều}

Trầm tích tầng mặt bãi triều và trầm tích lắng đọng trên bẫy chủ yếu là trầm tích là hạt mịn có kính thước nhỏ hơn $0,100 \mathrm{~mm}$, gồm có 3 loại là bột lớn, bùn bột nhỏ và bùn sét bột. Bột lớn có đường kính $(\mathrm{Md})=0,057-0,087 \mathrm{~mm}$, độ chọn lọc $\left(\mathrm{S}_{0}\right)=2,768-4,611$, độ lệch $\left(\mathrm{S}_{\mathrm{k}}\right)=0,138-0,233$. Bùn bột nhỏ có $\mathrm{Md}=0,010-0,025 \mathrm{~mm} ; \mathrm{S}_{0}=3,118-4,007 ; \mathrm{S}_{\mathrm{k}}$ $=0,608-1,767$. Bùn sét bột có $\mathrm{Md}=0,008-0,009 \mathrm{~mm} ; \mathrm{S}_{0}=3,803-4,170 ; \mathrm{S}_{\mathrm{k}}=2,332-$ 2,754 .

Hầu hết các loại trầm tích bẫy và tầng mặt đều có độ chọn lọc kém $\left(\mathrm{S}_{0}>2,2\right)$ thể hiện môi trường lắng đọng khá yên tĩnh, chỉ chịu tác động của động lực mạnh khi có điều kiện thời tiết bất thường.

\section{Tốc độ tích lũy khối lượng trầm tích trên bãi triều}

Bãi triều Bàng La về mùa mưa có tốc độ tích tụ khối lượng trầm tích dao động trong khoảng $0,07-13,76 \mathrm{~g} / \mathrm{cm}^{2} /$ năm, trung bình là $7,06 \mathrm{~g} / \mathrm{cm}^{2} /$ năm. Về mùa khô tốc độ tích tụ khối lượng trầm tích dao động trong khoảng $1,34-6,98 \mathrm{~g} / \mathrm{cm}^{2} /$ năm, trung bình 4,50 $\mathrm{g} / \mathrm{cm}^{2} /$ năm (hình 2). 


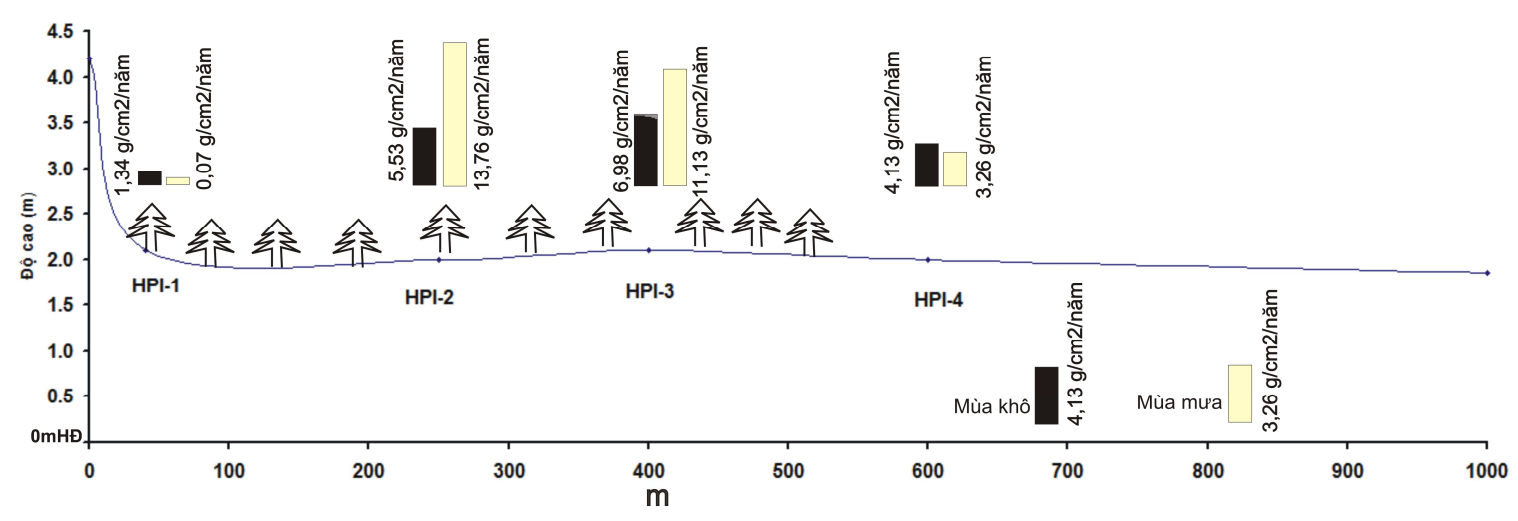

Hình 2: Tốc độ tích tụ khối lượng trầm tích trên bãi triều Bàng La

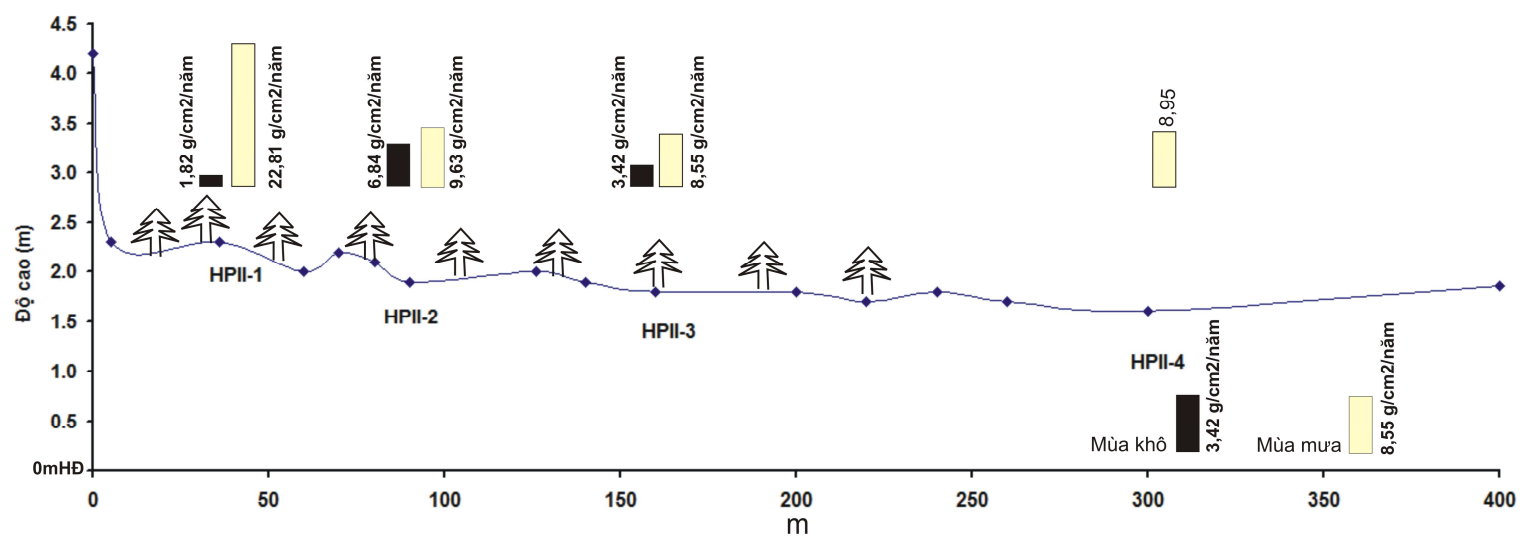

Hình 3: Tốc độ tích tụ khối lượng trầm tích trên bãi triều Ngọc Hải

Bãi triều Ngọc Hải về mùa khô có tốc độ tích tụ khối lượng trầm tích dao động trong khoảng $1,82-6,84 \mathrm{~g} / \mathrm{cm}^{2} /$ năm, trung bình $4,03 \mathrm{~g} / \mathrm{cm}^{2} /$ năm. Về mùa mưa tốc độ tích tụ khối lượng trầm tích dao động trong khoảng $8,55-22,81 \mathrm{~g} / \mathrm{cm}^{2} /$ năm, trung bình 12,48 $\mathrm{g} / \mathrm{cm}^{2} /$ năm (hình 3).

\section{Tuổi trầm tích trong lỗ khoan và tốc độ bồi tụ nổi cao bãi triều}

Tuổi trầm tích trong lỗ khoan thu ở bãi triều Bàng $\mathrm{La}(0-40 \mathrm{~cm})$ có tuổi từ năm 1894 - 2008. Tốc độ bồi tụ nổi cao của bãi triều 0,13 - $1,18 \mathrm{~cm} / \mathrm{năm}$, trung bình $0,52 \mathrm{~cm} / \mathrm{năm}$ (hình 4, hình 5). 


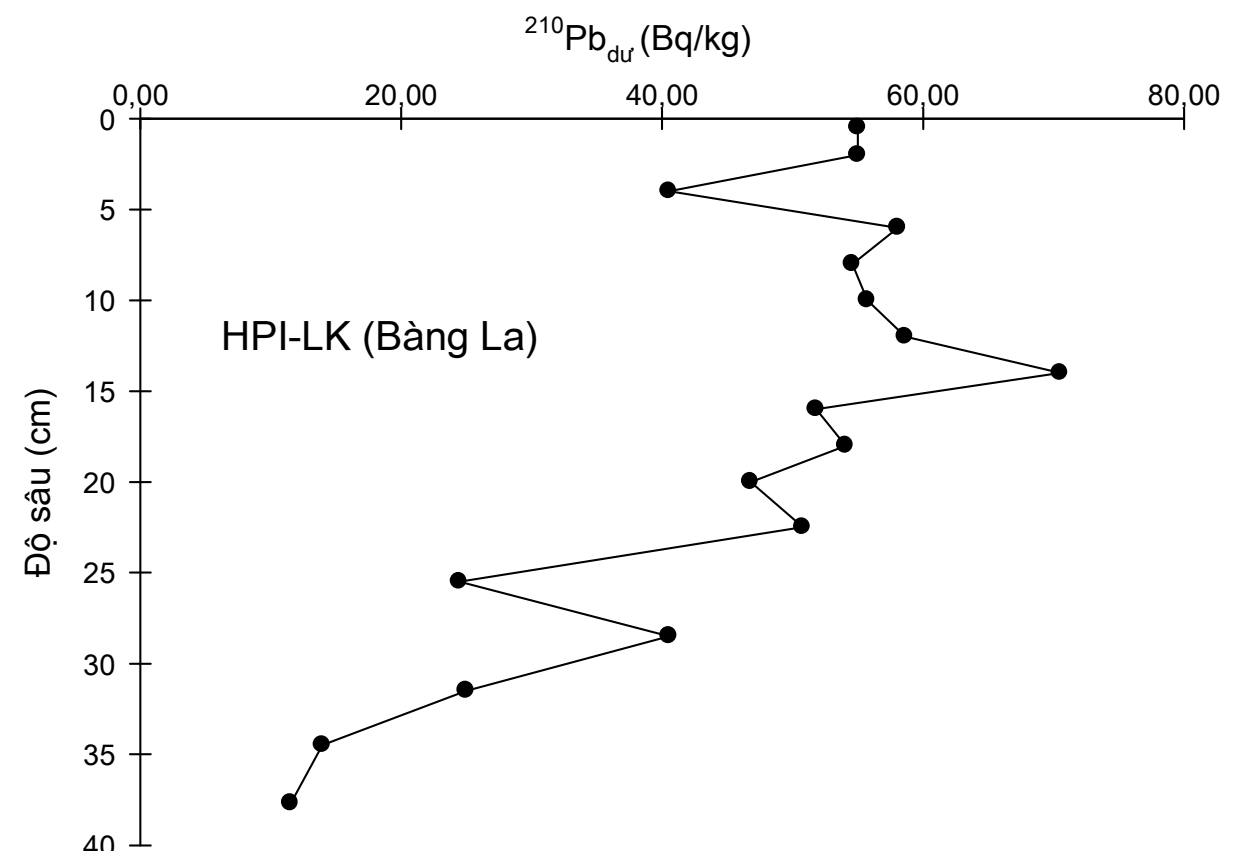

Hình 4: Hoạt độ ${ }^{210} \mathrm{~Pb}_{\mathrm{du}}$ trong lỗ khoan bãi triều Bàng La

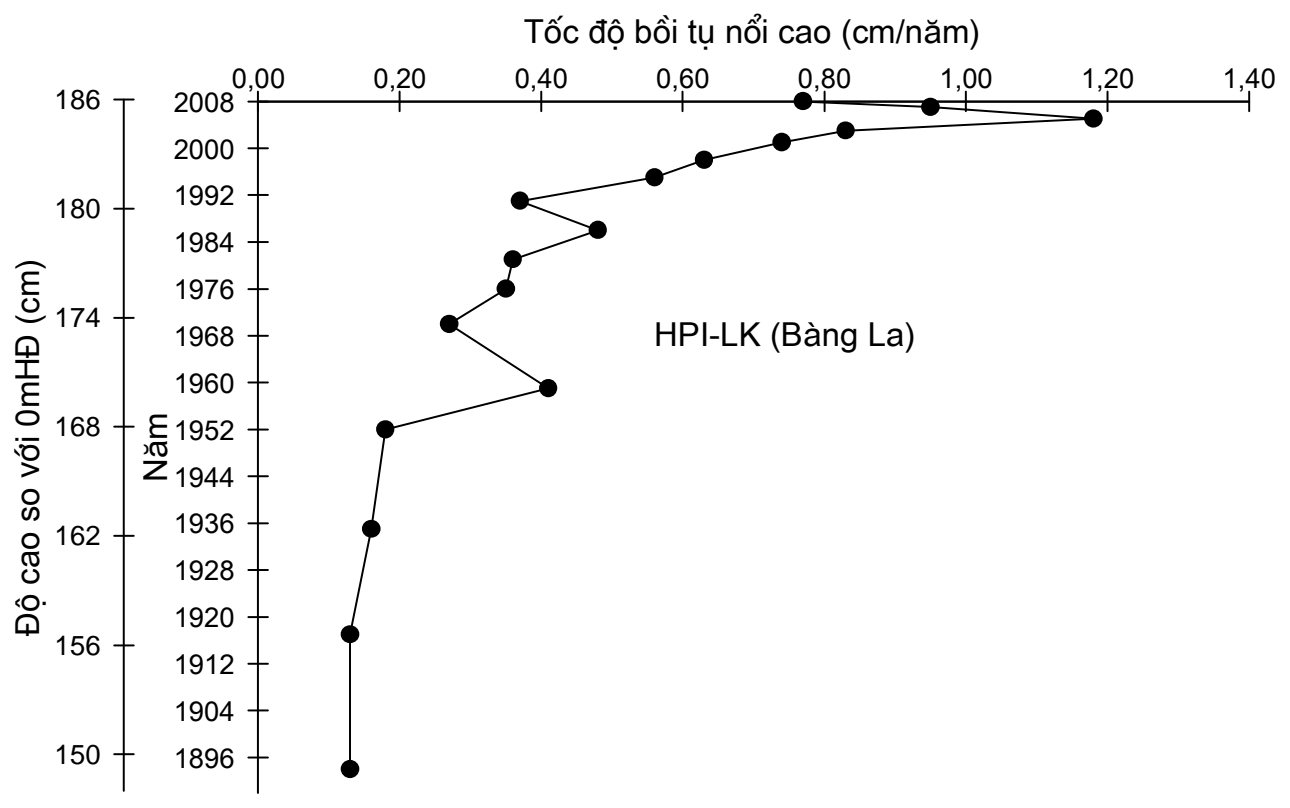

Hình 5: Tốc độ bồi tụ nổi cao bãi triều Bàng La 
Tuổi trầm tích lỗ khoan bãi triều Ngọc Hải $(0-60 \mathrm{~cm})$ có tuổi từ năm $1935-2008$. Tốc độ bồi tụ nổi cao bãi triều dao động trong khoảng $0,26-15,00 \mathrm{~cm} / \mathrm{năm}$, trung bình 2,94 cm/năm (hình 6, hình 7).

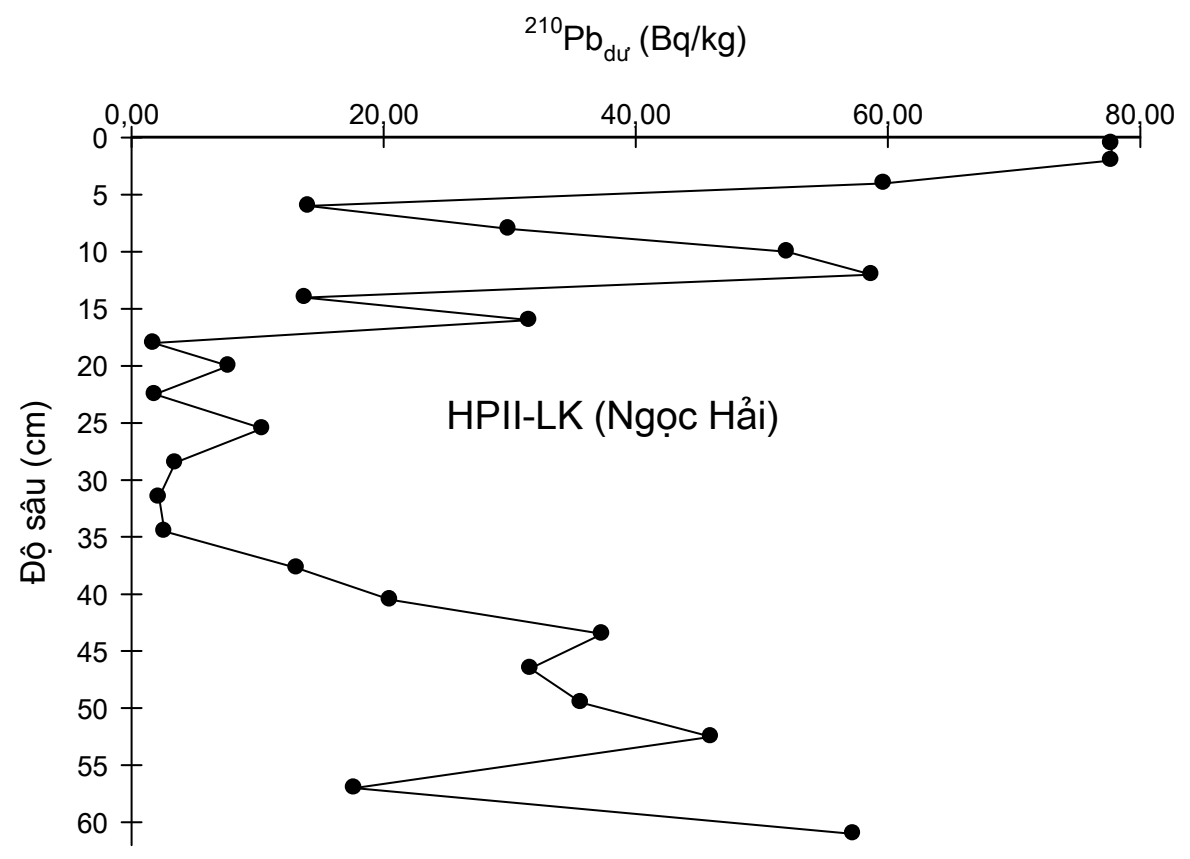

Hình 6: Hoạt độ ${ }^{210} \mathrm{~Pb}_{\mathrm{du}}$ trong lỗ khoan bãi triều Ngọc Hải

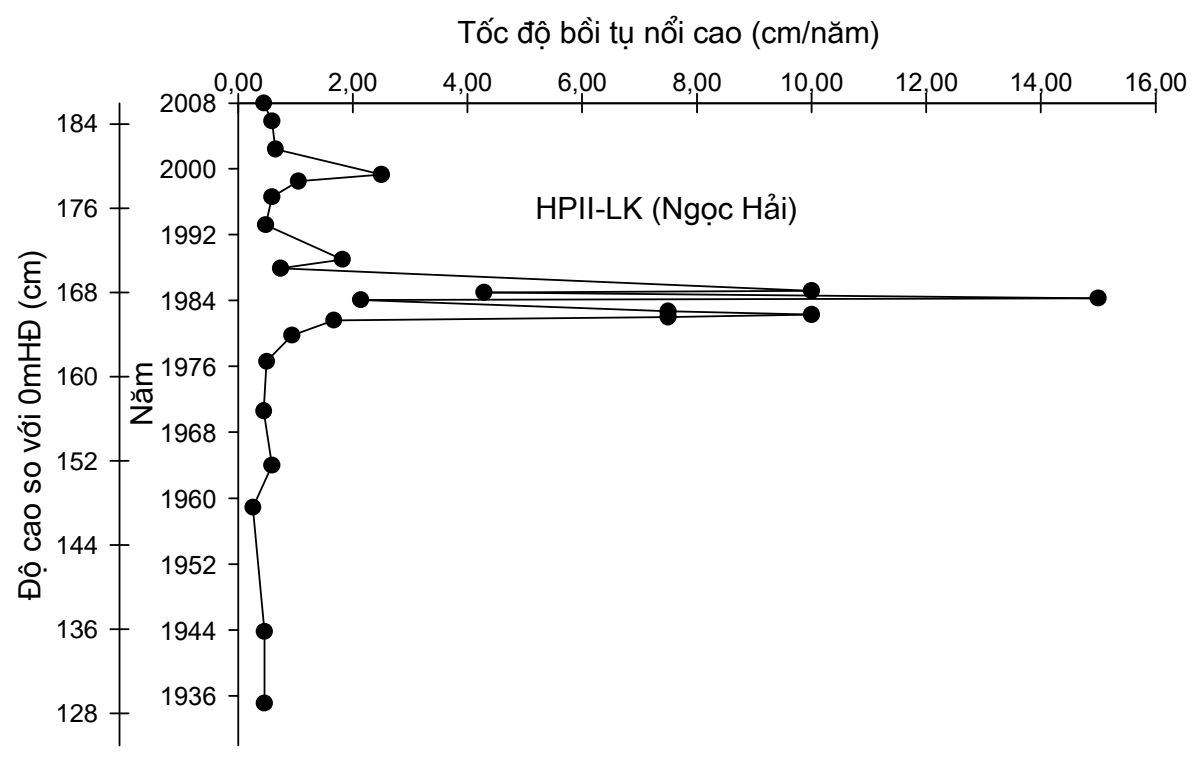

Hình 7: Tốc độ bồi tụ nổi cao bãi triều Ngọc Hải 


\section{THẢO LUẬN}

Sự thay đổi của hoạt độ ${ }^{210} \mathrm{~Pb}$ quan sát thấy trong cột lỗ khoan trầm tích phản ánh sự thay đổi về môi trường lắng đọng trầm tích. Nguồn cung cấp trầm tích, các quá trình thuỷ văn và điều kiện địa hình là những yếu tố quyết định đến tốc độ tích tụ khối lượng và độ nổi cao bãi triều.

Bãi triều Bàng La có sự thay đổi môi trường trầm tích mang tính chất từ từ của quy luật tự nhiên ít mang tính đột ngột ảnh hưởng của hoạt động nhân sinh. Dựa vào tốc độ bồi tụ nổi cao (hình 5) chúng tôi chia ra làm 4 giai đoạn lắng đọng trầm tích cơ bản. Giai đoạn 1 diễn ra từ 1894 - 1952 biểu hiện bằng tốc độ bồi tụ nổi cao của bãi triều nhỏ $(0,13-0,18$ cm/năm); Giai đoạn 2 từ 1952 - 1991, tốc độ bồi tụ nổi cao $(0,27-0,48 \mathrm{~cm} / \mathrm{năm})$ trong giai đoạn này có sự thay đổi phức tạp không theo xu hướng cùng tăng hoặc cùng giảm tăng giảm về tốc độ bồi tụ nổi cao của bãi triều; Giai đoạn 3 từ 1991 - 2005, tốc độ bồi tụ nổi cao tăng dần $(0,56-1,18 \mathrm{~cm} / \mathrm{năm})$; Giai đoạn 4 từ 2005 - 2008, tốc độ bồi tụ nổi cao có xu hướng giảm đi $(0,77$ - 0,95cm/năm) so với giai đoạn 1991 - 2005.

Bãi triều Ngọc Hải trên cơ sở tốc độ bồi tụ nổi cao (hình 7) chúng tôi chia ra được 4 giai đoạn lắng đọng trầm tích cơ bản. Giai đoạn 1 từ 1935 - 1981, có tốc độ bồi tụ nổi cao bãi triều nhỏ $(0,26-0,94 \mathrm{~cm} /$ năm); Giai đoạn 2 từ 1981 - 1985, giai đoạn này vừa ngắn lại mang tính chất đột ngột do ảnh hưởng của hoạt động đắp đập Đình Vũ, đê Đường 14 diễn ra vào năm 1979 - 1981 (Trần Đức Thạnh và nnk, 1992) làm cho tốc độ bồi tụ nổi cao tăng đột ngột (1,67 - 15,00 cm/năm); Giai đoạn 3 từ 1985 - 1999, tốc độ bồi tụ nổi cao có sự ổn định $(0,48-2,50 \mathrm{~cm} / \mathrm{năm})$; Giai đoạn 4 từ 1999 - 2008, tốc độ bồi tụ nổi cao giảm dần $(0,45-0,65$ cm/năm).

Các tài liệu được công bố trước đó cũng đã chỉ ra giai đoạn 1991 - 2005 là bồi tụ ở bãi triều Bàng La diễn ra khá mạnh (Bùi Văn Vượng và Đinh Văn Huy, 2006). Khi độ cao của bãi triều đã đạt đến độ cao nhất định thì tốc độ bồi tụ nổi cao lại giảm xuống điều đó có thể giải thích thông qua thời gian ngập triều của vị trí được ngập nước ít, yếu tố động lực khác của biển như sóng, dòng chảy tác động đến bãi triều thay đổi.

So sánh với các khu vực khác ở ven bờ Việt Nam, có thể thấy tốc độ bồi tụ nổi cao của các bãi triều Bàng La và Ngọc Hải lớn hơn với đầm Tam Giang - Cầu Hai và thềm lục địa miền Trung Việt Nam, nhưng thấp hơn ở vùng cửa sông Ba Lạt. So sánh với một số nơi trên Thế giới thì tốc độ bồi tụ nổi cao của các bãi triều Bàng La và Ngọc Hải thấp hơn (bảng 1). 
Bảng 1: So sánh tốc độ bồi tụ nổi cao của bãi triều với các thủy vực khác

\begin{tabular}{|c|c|c|c|c|}
\hline TT & Khu vực & $\begin{array}{c}\text { Tốc độ bồi tụ nổi } \\
\text { cao (cm/năm) }\end{array}$ & Tác giả & Ghi chú \\
\hline 1 & $\begin{array}{l}\text { Bàng La và Ngọc } \\
\text { Hải }\end{array}$ & $0,52-2,94$ & $\begin{array}{l}\text { Trong nghiên cứu } \\
\text { này }\end{array}$ & $\begin{array}{l}\text { Bãi triều ngoài } \\
\text { rừng ngập mặn }\end{array}$ \\
\hline \multirow[t]{2}{*}{2} & \multirow[t]{2}{*}{ Cửa sông Ba Lạt } & $0,70-3,00$ & $\begin{array}{l}\text { Van Den Bergh } \\
\text { G.D. et al., } \\
\text { 2007b. }\end{array}$ & $\begin{array}{l}\text { Đáy có độ sâu } 25 \\
\text { m. }\end{array}$ \\
\hline & & $0,18-0,24$ & $\begin{array}{l}\text { Janssen-Steldera } \\
\text { B.M. et al., } 2002 .\end{array}$ & $\begin{array}{l}\text { Trong rừng ngập } \\
\text { mặn. }\end{array}$ \\
\hline 3 & $\begin{array}{l}\text { Đầm Tam Giang - } \\
\text { Cầu Hai }\end{array}$ & $0,31-0,60$ & $\begin{array}{l}\text { Albertazzi S. et } \\
\text { al., } 2007\end{array}$ & $\begin{array}{l}\text { Đầm phá có độ } \\
\text { sâu } 1,5-2,0 \mathrm{~m}\end{array}$ \\
\hline 4 & $\begin{array}{l}\text { Thềm lục địa miền } \\
\text { Trung Việt Nam }\end{array}$ & $0,20-0,47$ & $\begin{array}{l}\text { Witold } \\
\text { Szczuciński et al., } \\
2009\end{array}$ & $\begin{array}{l}\text { Đáy có độ sâu } 20 \\
\text { - } 134 \text { m }\end{array}$ \\
\hline \multirow[t]{2}{*}{5} & \multirow{2}{*}{$\begin{array}{l}\text { Cửa sông Trường } \\
\text { Giang, Trung Quốc }\end{array}$} & $0,60-5,00$ & \multirow{2}{*}{$\begin{array}{l}\text { Taoyuan Wei et } \\
\text { al., } 2007\end{array}$} & Bãi triều cao. \\
\hline & & $0,80-6,30$ & & Phần dưới triều. \\
\hline 6 & $\begin{array}{l}\text { Các thủy vực của } \\
\text { Malaysia }\end{array}$ & $1,57-8,64$ & $\begin{array}{l}\text { Theng L.T. et al., } \\
2003\end{array}$ & $\begin{array}{l}\text { Vũng vịnh có độ } \\
\text { sâu 5,0 - 35,1 m }\end{array}$ \\
\hline
\end{tabular}

Hầu hết các kết quả quan trắc tốc độ tích tụ khối lượng trầm tích đều thấy về mùa mưa lớn hơn mùa khô. Tốc độ tích tụ khối lượng trầm tích lớn nhất gặp trong rừng ngập mặn, ngoài rừng ngập mặn có tốc độ tích lũy khối lượng trầm tích nhỏ hơn. Sự phụ thuộc vào nguồn cung cấp vật liệu trầm tích và tốc độ thể hiện khá rõ, các nghiên cứu trước cho thấy lưu lượng nước cung cấp cho các sông về mùa mưa chiếm đến $80 \%$ tổng lượng nước cung cấp cho dải ven bờ (Nguyễn Văn Cư, 2006).

\section{KẾT LUẬN}

Bãi triều Bàng La hiện có tốc độ tích tụ khối lượng trầm tích về mùa khô dao động trong khoảng $1,34-6,98 \mathrm{~g} / \mathrm{cm}^{2} / \mathrm{năm}$, trung bình $4,50 \mathrm{~g} / \mathrm{cm}^{2} / \mathrm{năm}$; về mùa mưa tốc độ tích tụ khối lượng trầm tích dao động trong khoảng $0,07-13,76 \mathrm{~g} / \mathrm{cm}^{2} /$ năm, trung bình 7,06 
$\mathrm{g} / \mathrm{cm}^{2} /$ năm. Bãi triều Ngọc Hải tốc độ tích tụ khối lượng trầm tích về mùa khô dao động trong khoảng $1,82-6,84 \mathrm{~g} / \mathrm{cm}^{2} /$ năm, trung bình $4,03 \mathrm{~g} / \mathrm{cm}^{2} / \mathrm{năm}$; về mùa mưa tốc độ tích lũy khối lượng trầm tích dao động trong khoảng $8,55-22,81 \mathrm{~g} / \mathrm{cm}^{2} /$ năm, trung bình 12,48 $\mathrm{g} / \mathrm{cm}^{2} /$ năm.

Tốc độ bồi tụ nổi cao của bãi triều Bàng La dao động trong khoảng 0,13 - 1,18 $\mathrm{cm} /$ năm (1894 - 2008), trung bình $0,52 \mathrm{~cm} /$ năm. Bãi triều Ngọc Hải có tốc độ bồi tụ nổi cao dao động trong khoảng 0,26 - 15,00 cm/năm, trung bình 2,94 cm/năm.

Các bãi triều Bàng La và Ngọc Hải đã trải qua 4 giai đoạn lắng đọng trầm tích kể từ năm 1894 - 2008 đối với bãi triều Bàng La và 1936 - 2008 đối với bãi triều Ngọc Hải. Ảnh hưởng của con người qua việc đắp đập Đình Vũ, đê Đường 14 được ghi nhận trong lỗ khoan ở bãi triều Ngọc Hải giai đoạn 1981 - 1985 biểu hiện ở tốc độ bồi tụ nổi cao bãi triều tăng lên đột biến.

\section{TÀI LIỆU THAM KHẢO}

1. $\quad$ Albertazzi S., Bellucci L.G., Frignani M., Giuliani S., Romano S., Nguyen Huu Cu, 2007. ${ }^{210} \mathrm{~Pb}$ and ${ }^{137} \mathrm{Cs}$ in sediment of Central Vietnam coastal lagoons: Tentative assessment of accumulation rate. Journal of Marine Science and Technology Supplement 1: 73-81.

2. Appleby P.G., Oldfield F., 1978. The caculation of ${ }^{210} \mathrm{~Pb}$ dates assuming a constant rate of supply of unsupported ${ }^{210} \mathrm{~Pb}$ to sediment. Catena 5: 1-8.

3. Appleby P.G., Oldfield F., 1992. Applications of ${ }^{210} \mathrm{~Pb}$ to sedimentation studies. In: Ivanovich M., Harmon R.S. (Eds.), Uranium Series Disequilibrium Application to the Earth. Clarendon Press, Oxford: 731-778.

4. Nguyễn Văn Cư, 2006. Bãi bồi ven biển cửa sông Bắc bộ Việt Nam. NXB. Khoa học Tự nhiên và Công nghệ, Hà Nội.

5. Phan Son Hai, et al., 1999. Determination of Pb-210 in sediment and it's application for estimation of dating sediments. Tạp chí phân tích Hoá, Lý và Sinh học, tập 4, số 4: 40-42.

6. Janssen-Steldera B.M. , P.G.E.F. Augustinusa, W.A.C. van Santena, 2002. Sedimentation in a coastal mangrove system, Red River Delta, Vietnam In: Johan C. Winterwerp, Cees Kranenburg (Eds.), Fine Sediment Dynamics in the Marine Environment Elsevier: 455-467. 
7. Krishnaswami S., Lal D., Martin J.M., Meybeck M., 1971. Geochronology of lake sediments. Earth and Planet Science Letter Vol. 11: 407-414.

8. Trần Đình Lân, Trần Đức Thạnh, 1991. Hình thái, phân bố trầm tích và đặc điểm bồi tụ bãi bồi ven biển huyện Kim Sơn. Tuyển tập Tài nguyên và Môi trường biển, tập I, trang 33-39. NXB. Khoa học và Kỹ thuật, Hà Nội.

9. Lisitzin A.P., 1986. Principles of geological mapping of marine sediments. Unesco Reports in Marine Science N.33: 1-111

10. Đặng Hoài Nhơn, 2008. Lắng đọng trầm tích lơ lửng trên rạn san hô khu vực Hải Phòng - Quảng Ninh. Báo cáo chuyên đề. Lưu trữ tại Viện Tài nguyên và Môi trường biển: 1-11.

11. Robbins J.A., 1978. Geochemiscal and geophysical applications of radioactive lead. In: Nkagru J. (Ed.), The Biogeochemistry of Lead in the Environment. Elsevier, The Netherlands: 285-393

12. Santen P.V, Augustinus P.G.E.F., Janssen-Steldera B.M., Quartel S., Trí N.H., 2007. Sedimentation in an estuarine mangrove system. Journal of Asian Earth Sciences, Vol. 29: 566-575.

13. Taoyuan Wei, Zhongyuan Chen, Lingyun Duan, Jiawei Gu, Yoshiki Saito, Weiguo Zhang, Yonghong Wangd and Yutaka Kanaie, 2007. Sedimentation rates in relation to sedimentary processes of the Yangtze Estuary, China Estuarine, Coastal and Shelf Science Vol. 71: 37-46.

14. Trần Đức Thạnh, Nguyễn Đức Cự, Nguyễn Chu Hồi, Trần Đình Lân, Nguyễn Thị Phương Hoa, Đinh Văn Huy, Phạm Văn Huấn, Vũ Đình Tiến, Phạm Thanh Thúy, Nguyễn Quang Tuấn, Phạm Văn Vy, Đỗ Kim Xuân, 1992. Điều tra khảo sát mức độ bồi tụ để đánh giá tính khả thi của việc xây dựng bến cá Ngọc Hải. Báo cáo tổng kết đề tài. Lưu trữ tại Viện Tài nguyên và Môi trường biển, Hải Phòng.

15. Theng L.T., Ahmad Z., Mohamed C.A.R., 2003. Estimation of sedimentation rate using ${ }^{210} \mathrm{~Pb}$ and ${ }^{210} \mathrm{Po}$ at the coastal water of Sabah, Malaysia. Journal of Radioanalytical and Nuclear Chemistry Vol. 256: 115-120.

16. Nguyễn Quang Tuấn, Nguyễn Chu Hồi, 1999. Lắng đọng trầm tích trên rạn san hô vùng ven biển Cát Bà-Hạ Long. Trong: Đặng Ngọc Thanh (chủ biên), Tuyển tập Hội nghị khoa học công nghệ biển toàn quốc lần thứ IV. NXB. Thống kê, Hà Nội: 669707. 
17. Van den Bergh G.D., Boer W., Schaapveld M.A.S., Duc D.M., van Weering Tj.C.E., 2007a. Recent sedimentation and sediment accumulation rates of the $\mathrm{Ba}$ Lat prodelta (Red River, Vietnam). Journal of Asian Earth Sciences Vol. 29: 545557.

18. Bùi Văn Vượng, Đinh Văn Huy, 2006. Nghiên cứu biến động địa hình ven bờ tây nam Đồ Sơn. Tuyển tập Tài nguyên và Môi trường biển, tập XII, trang 41-62. NXB. Khoa học và Kỹ thuật, Hà Nội.

19. Witold Szczuciński, Karl Stattegger, Jan Scholten, 2009. Modern sediments and sediment accumulation rates on the narrow shelf off central Vietnam, South China Sea. Geo-Marine Letters Vol. 29: 47-59.

\section{SEDIMENTATION IN THE BANG LA AND NGOC HAI INTERTIDAL ZONES, HAI PHONG}

\section{DANG HOAI NHON, PHAN SON HAI, HOANG THI CHIEN, NGUYEN THI KIM ANH, BUI VAN VUONG, NGUYEN NGOC ANH, PHAM HAI AN, VU MANH HUNG}

Summary: Sedimentation in the Bang La and Ngoc Hai intertidal zones was carried out to study by sedimentary traps and sediment cores. Accumulation rate of sediment calculated by traps in September, 2008 and April, 2009, chronology of sediment cores use $210 \mathrm{~Pb}$ and $\mathrm{CRS}$ model for calculated.

Sediments deposited in traps and surface sediments in intertidal zone are coarse aleurites $(M d=0.057-0.087 \mathrm{~mm})$, fine aleurites $\mathrm{muds}(\mathrm{Md}=0.010-0.025 \mathrm{~mm})$, aleuritic pelitic muds $(\mathrm{Md}=0.008-0.009 \mathrm{~mm})$.

In the Bang La intertidal zone, accumulation rate of sediments in rainy season was in a range from $0.07-13.76 \mathrm{~g} / \mathrm{cm} 2 / y e a r$, in the dry season in a range from $1.34-6.98 \mathrm{~g} / \mathrm{cm} 2 / y e a r$. In the Ngoc Hai intertidal zone, accumulation rate of sediments in rainy season was in a range from 8.55 - $22.81 \mathrm{~g} / \mathrm{cm} 2 / y e a r$, in dry season in a range from 1.82 - $6.84 \mathrm{~g} / \mathrm{cm} 2 /$ year.

Sedimentation rate in the Bang La intertidal zone was in a range from $0.13-1.18$ $\mathrm{cm} /$ year in period 1894 - 2008, in the Ngoc Hai intertidal zone was in a range from 0.13 $15.00 \mathrm{~cm} /$ year in period 1935-2008.

Sedimentation processes in intertidal zone is depend on vegetations and geomorphology, and the highest accumulation rate of sediments is in mangrove forest, lower accumulation rate of sediments is outside mangrove forest.

Ngày nhận bài: 7 - 12 - 2010

Ngưòi nhận xét: PGS. TS. Trần Đức Thạnh 